Negative results were obtained in all non-pulmonary cases.

The tubercle bacilli present in the gastric contents were all of buman type.

The presence of tubercle bacilli in the gastric contents establishes a definite diagnosis.

Segregation of such cases is advocated.

Gastric lavage should be a routine diagnostic measure.

It should be done on successive days, and frequently during treatment.

We are greatly indebted to Dr. D. W. Fenwick Jones, medical superintendent of the Adelina Patti Hospital, for allowing us the use of the case records and for much valuable advice and assistance. Our thanks are also due to Dr. D. A. Powell, principal medical officer, Prof. Tytler and Dr. Ruth Milne of the Central Tuberculosis Laboratory, and to Sister Powell, who carried out so successfully the actual procedure of gastric lavage. REFERENCES

Armand-Delille, P. F. (1927). Amer. J. Dis. Child., 34, 547. Collis. W. R. F., and Brockington, C. F. (1933). Lancet, 1, 127.

Meunier, H. (1898). Presse mél., 2, 81.

Munro, W. T. (1938). Edinb. med.J., 45, 226

Poulsen, V., Jensen, K. A., and Husted, E. (1929). Amer. J. Dis. Child., 37, 900.

\section{GROUP PSYCHOTHERAPY}

BY

\section{J. BIERER, M.D.Vienna \\ Honorary Psychotherapist, Runwell Hospital}

During one year's psychotherapeutic work at the Runwell Hospital for Nervous and Mental Diseases and in the Clinics of the Southend General and East Ham Memprial Hospitals I-treated 70 neurotic and early psychotic patients with deep and intensive psychotherapy. Of these patients $87 \%$ were cured or sufficiently improved to be discharged. I would like to make some observations on the methods employed in an attempt to show that group psychotherapy is more practicable than has been believed hitherto-and, here at the outset, may I make clear the distinction between three different terms I use : Analysis will refer to all methods and degrees of analysis, except that particular method introduced and practised by Freud and his followers, for which psycho-analysis is reserved. Psychotherapy is, of course, used to designate any or all of the existing psychological methods of treatment.

\section{Disadvantages of Freud's Method}

Freud, in his revolt against the overpowering influence of the physician on the patient which results from hypnosis, tried by his analysis to create a form of treatment in which the personal influence of the physician was at the minimum, but which had the great disadvantage that the treatment became so lengthy that it was impracticable for most people. There were three other disadvantages which reduced the usefulness of Freudian psycho-analysis :

1. Nearly every neurotic and psychotic is, as part of his illness, in a state of reduced activity (activity in the sense of participation in the different spheres of social life). To keep him in this state-as he must be kept, because the psychoanalys:s lasts so long-will probably help him to make that unhealthy state a chronic one.

2. Every neurotic or psychotic is unable to be independent. He has either never gained his independence or he has lost it. To keep such a patient for a long time in dependence upon a psycho-analyst simply tends to make this state, too, a chronic one-even, unfortunately, in many cases an incurable one.

3. The type of patient who is, a priori, suitable for psychoanalysis is very limited in number, as, apart from considerations of the length of treatment and the heavy expense incurred, many neurotics and early psychotics are not accessible by free association, which is, of course, a basic part of psycho-analysis : also, many of them do not possess the degree of intelligence necessary for a successful treatment by analysis.

\section{Method used in the Present Series}

In contrast to this Freudian method, the main features of my system were as follows: $(a)$ shortening of the time of analysis; $(b)$ the combined usage of individual and group treatment $;(c)$ the introduction of a method of situational treatment; (d) the introduction of new forms of social treatment; and $(e)$ bridging the gulf which often exists between full insight and cure in psycho-analytical treatment.

With regard to the shortening of the time of the analysis, the question arises: Is it possible, in a short time, to get a more or less complete knowledge of the deeper causesi.e., the subconscious background of the patient? The answer seems to be that it is possible, but only if one accepts the conception that there is a general attitude exclusive to every individual. A "general attitude" is not the sum of single attitudes, which varies at the moment of the event (this would be behaviour), but is usually a previously fixed and therefore anticipated attitude towards all situations that are met with. It is formed in the first years of childhood, and though later events may modify it, even to an extreme degree, they never change it completely. Where it has become a hindrance to the patient it can be so modified for good by intensive psychotherapy that it will cease to cause him any further trouble.

But how can this general attitude, and through it the subconscious background of the patient, be ascertained? My method was as follows :

All patients are asked to write down their earliest childhood recollections. At first many are doubtful if they can do this, but I have hardly ever seen any who have not been able to do so. They are then asked to write, in instalments, their aims and ambitions (especially between the ages of 10 and 14), their likes, dislikes, and dreams. What I learn from these documents, together with the exact social history, an interview with a relation and two or three sittings with the patient, enables me to get a picture of the subconscious background.

This approach differs from Freud's psycho-analysis in that: (1) It takes into account the whole life-life in the sense of psyche, body, and environment. (2) There is no synchronization in the knowledge of the deep causes of the illness by the therapist and the patient (the therapist knows this first), whereas in psycho-analysis the patient and the physician learn more or less at the same rate. (3) It does not agree that "making conscious" is a means of effecting a cure, even by way of transference and subsequent solving of the transference situation, as happens in psycho-analysis. (4) It avoids the Scylla and Charybdis of the theory of symbolism which is so general, on the one hand, and the interpretation of the psycho-analyst which is so personal, on the other, by assuming that there is one "general attitude" in every person (this being an individual but at the same time stable factor).

This approach uses the process of analysis, but the reason why psycho-analysts did not employ it is that in a short analysis the psychotherapist gets the knowledge of the deeper background but the patient does not. Diagnosis is therefore not identical with cure-and in order to obtain a cure the psychotherapist would somehow have to transfer that knowledge to the patient, would have to lead him, and would endanger the treatment by becoming an overpowering factor.

\section{Situational Treatment}

In order to avert that danger a new avenue must be found. This new avenue, in my opinion, is situational treatment, which must be clearly distinguished from institutional treatment. Under "situational treatment" I 
include any individually directed but impersonal measures undertaken by the psychotherapist and his assistants with the aim of achieving a certain change of attitude in the patient, they having a full knowledge of the analytical background of that particular patient while he himself is ignorant of it.

In situational treatment the patient does not get knowledge about his subconscious, but he experiences the situation which makes him change his attitude. For example, let us say that a boy is afraid to swim : he is afraid because he believes he cannot swim; he cannot swim because he is afraid. The longer he stands on the edge of the water the more frightened he becomes, and that is a vicious circle. I do not say that a long-standing psycho-analysis would not have the effect of making him jump into the water and try to swim; in some cases it certainly would produce the desired result, but this can, however, be procured in a simpler way. A clever swimming instructor who understood how to put the boy into the water could turn him on his back in such a way that he would be completely convinced that no harm could come to him so long as he was supported by the strength of the swimming instructor who was holding him; for the boy who before was so frightened would have found out that it was possible to lie on the water without doing anything, and without sinking : his fear would disappear, the vicious circle would be broken, and the teaching of the strokes would become much easier than if the instructor had first tried to teach them without taking into consideration the natural-or in many cases the completely abnormal-fear. Lying on the strong hands of the teacher would convince the boy much more than the most clever argument or the longest analysis. "Situations" which occur in everybody's life and which influence lives decisively can be artificially arranged, as in this instance, and so can become an important method of psychotherapy.

By "institutional treatment" we understand any impersonal measures undertaken by an institution or its agents -having sometimes a knowledge of the state of the individual patient (but without the knowledge of the analytical background necessary for situational treatment)-with the aim of achieving a certain change of attitude in him. Occupational therapy by itself is institutional treatment; but special occupational therapy chosen in accordance with the analysis of that particular patient, and managed or led to meet the analytical desires of that patient, is situational treatment.

An 18-year-old schizophrenic, who was dressed and fed by his mother for his whole life, and could not therefore achieve the slightest independence from her, was treated successfully by specially arranged occupational (i.e., situational-occupational) therapy in the following manner:

In order to allow the patient to develop his strong desire for identification with his father, it was arranged that the psychotherapist should take him as his assistant to work in the patients' garden and, by letting him act as leader of the gang working there, should give him the opportunity of experiencing the strong-father identification for which he had longed. It is easy to see in this case that analysis had to be performed and the special situation arranged so that through identification with the strong male personality (i.e., the psychotherapist) the patient was enabled to become active and so, without knowledge but through the process of the situation, to achieve the independence the lack of which was the cause of all his symptoms.

Again, to take another example, physical training by itself is institutional treatment, but if, as in occupational therapy, it is used in the individual and analytical way it can become situational treatment.

A woman aged 26 was for many months in a mental hospital with the symptoms of severe claustrophobia. She could not move outside the hospital, and, in spite of the length of her stay there, did not show any signs of improvement. She was very quiet and dull, and not very sociable. She had not had a strict upbringing; on the contrary, she had been very much spoilt by her mother. Before coming to the hospital she was a shorthand-typist in a lawyer's office. No approach, whether by psycho-analysis or by individual psychotherapy, had been in the least successful. The girl had obtained her situation by replacing her sister when she married. It was found out, after a time, that she was unhappy in her work, and the reason for her unhappiness was that her employer, the lawyer, was foolish enough to tell her nearly every day how wonderful her sister had been in the same employment.

Her one desire in life was to become a teacher of physical training (this aim had really some deeper connexions with her mysterious father, who appeared only once in a few years, merely to disappear again in the same way after a short time), and although she was shy, unintelligent, and unsociable, she was put into the phys.cal training department as assistant to the teacher. She made such good progress that after a few months, even before she was completely cured, a post was found for her in another mental hospital in Scotland, as assistant to the physical training teacher there. To the surprise of everyone concerned, the shy girl undertook the long journey to Scotland, accepted the post, and after about a year passed her preliminary examination, by which time the claustrophobia had completely disappeared.

\section{The Social Club}

An important factor in situational treatment is the social treatment, and especially the self-governed social club as it was run in Runwell Hospital. Entertainments- for patients are arranged in all modern mental hospitals : that is institutional treatment. The basis of the "social club" idea is just the opposite: nothing is arranged for the patients, but everything is arranged and governed by them. By that one change a fundamental vicious circle is broken. When people get depressed or maniacal they must be shut up in mental hospitals because they are a danger to themselves or to others. Shutting them up gives some of them the proof that they are right in imagining themselves to be very ill. Some get stubborn and violent because they have no insight and do not want to be in the hospital : the more violent they become the more necessary is it to keep them in solitary confinement; the more they are segregated the greater is their violence; and so forth. To break that vicious circle involves accepting great responsibility. Many hospital authorities have already discovered that it is easier for the administration of the hospital and better for the patients' health if they are all set to work ; but there is still considerable hesitation in using restless or violent patients, especially for outdoor tasks. During a whole year of working with restless and violent patients (about thirty of them, with one attendant), and they using their normal garden tools, we did not have one accident, apart from a few efforts to escape. This courageous occupational therapy is one means of breaking the vicious circle. The social club is another.

A patient who was suffering from melancholia of many years' standing, and who was completely inaccessible, was so influenced by a concert arranged in the ward, and by a singer, that she got out of bed for the first time, and herself began to sing. From that moment she began to improve very slowly, and in course of time became an active member of the social club, so that she was ab'e to be decertified and discharged from the hospital a few months later. When she came to see me a short time ago she said spontaneously: "Do you know, Doctor, when I first began to make rapid progress? It was when I went to the social club-when I felt " 1 am no longer a nobody."

This expression does show forcibly how we forget that when patients are admitted to a mental hospital they are stripped of all their responsibilities, deprived of all independent action, and are in no way self-governing-in fact, they are made into "tools." The social club should be 
the first important step towards making the patient change his position from that of being an object to being a subject.

The social club is a part of the group treatment, by which we understand all measures in which more than two people co-operate and which are taken to prevent or heal psychological illnesses. Apart from the whole activity of the social club (which includes all kinds of entertainments, sports, games, and meetings, and the writing and printing of the patients' own magazine, etc., which are entirely inaugurated and governed by the patients themselves) it has one meeting over which the psychotherapist presides. Take as an example the club at Runwell Hospital-about 50 to 100 people take part in this particular meeting, which consists in discussing problems of personal importance, but in an impersonal way. The psychotherapist has to be as passive as possible, and takes part only when it is necessary to become active-as, for example, to contradict an unsuitable remark, or to finish a controversy between two very active members, or if it is found to be important from a therapeutic point of view, through questions, to make a passive member become more active, or to summarize the findings of the discussion and to put them before the meeting in a lucid manner.

Another form of group treatment that is used is the " circle." This is a weekly gathering of about ten patients (male and female together) at which the difficulties of one of the patients, who is present, are discussed, but never in a form in which any other patient would know whose problem it is, and in most cases in such an impersonal way that even the patient concerned does not become aware that it is his own problem. From my experience I have found that it is more beneficial to the patient if he feels only a similarity but is not consciously aware that it is he who is being discussed.

\section{Experiments in Group Psychotherapy}

As to the practical usage, we must say that, although the first experiments were made in 1905 by Pratt, group psychotherapy is not much used and is still in its infancy. The different experiments should be classified as follows :

Mass treatment, which consists in the overpowering of great numbers of people-as, for example, in mass hypnosis and mass suggestion (Brauchle).

Class treatment, which consists in trying to convince people by means of teaching, given in the form of lectures. This method was inaugurated by Pratt and Lazell, and continued by Buck, Harris, Sommers and Pouppirt, and Snowden.

Collective treatment, which includes all the systems that aim at more than superficial overpowering or teaching. They include: (a) group psycho-analysis, as used by Schilder and Wender ; $(b)$ group activity as a combination of institutional treatment, plus teaching, as used by Marsh; $(c)$ collective living together, as used by Emerson and Slavson; $(d)$ the situational treatment.

\section{Advantages claimed for Group Treatment}

The following advantages are mentioned by the different psychiatrists who used the various forms of group treatment :

Stepping-up of power of suggestion (for instance, in mass treatment, with which I personally do not agree). Spirit of co-operation in a group with a common objective. Fear of analyst removed. Socialization with reference to the fear of death. Patients feel that they cannot be so bad, as there are so many others in a similar state. Loss of self-consciousness. Establishment of rapport with leader. Friendly relations established among the members-of special value for those with limited social opportunities. Adequate therapy can be given to those who cannot afford frequent individual visits. Many employed patients can be seen without interfering with their regular-working hours. Re-education of relatives and friends.
The patients obtain practical experience in group adjustment and learn to accept responsibility for solution of problems. The psychotherapist has the opportunity of observing the patient in a social situation. Indirect suggestion can readily be given The group spirit carries the individual over temporary setbacks. Patients are aided in starting outside activities. The patients are roused to activity. Influence on the attendants.

The following advantages, especially so far as situational therapy is concerned, may be added : (1) The gulf between insight and cure which exists so often in psycho-analytical treatment can be bridged. (2) Patients in mental hospitals become independent, active, and "self-deciding," which helps a great deal in speeding up their cure. (3) It is made so much easier for many patients to solve their social problems.

\section{Conclusion}

After a year of experimental work it seems to me that the ideal team for applying this group therapy would consist of one expert psychotherapist with five assistants-two young physicians (or even one physician and one medical student who intend to become psychotherapists), two experienced occupational therapists, and one social worker. Such a team could easily treat two or three hundred patients a year and, in addition, could influence in a more superficial way many hundreds of old-standing psychotics. This would bring us a step further towards applying deep and intensive psychotherapy to larger groups of patients both in out-patient departments of general hospitals and to inmates of mental hospitals, and I am convinced that deep and intensive psychotherapy of the masses is nearer realization than heretofore has been thought possible.

\section{Summary}

In one year 70 neurotic and psychotic patients were treated with deep and intensive psychotherapy ; 87\% of them were discharged cured or improved.

This was effected by using a short form of analysis, by a combination of individual and group treatment, and by introducing a method of "situational treatment" and a new form of social treatment.

The results encourage me to believe that psychotherapy of the masses, especially in the combination of short but deep analysis plus situational and group treatment, is nearer realiza tion than has yet been thought possible.

I take pleasure in expressing my gratitude to Dr. R. StroemOlsen, physician-superintendent, for his helpful advice, for providing the facilities for this work, and for permission to publish the results. I also wish to thank Drs. Isabelle Little and E. Herbert for their constructive criticism, and Miss Doris Butcher for her great help.

$$
\text { BIBLIOGRAPHY }
$$

Abraham, Karl (1926). Int. Z. Psychoanal.

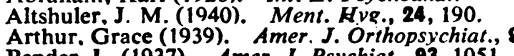

Arthur. Grace (1939). Amer.

and Woltmann, A. (1936). Amer. J. Orthopsychiat., 6, 341.

Bierer, J. (1940). J. ment. Sci., 86, 287.

(1940). Thid.. 86, 928

- and Haldane. F P. (1941). Ibid., 87, 419.

Brauchle, A (1927). Selhsiceinflusg., 22, 283.

(1939). Med. Klinik, 35, 40.

- (1940). Münch. med. Wschr., 87, 317.

Buck, R.W (1937). Ann. intern. Med., 11, 514.

Burrow. Trigant (1914). J. Amer. med. Ass., 62, 1876.

Burrow). Brit J. med Psychol., 8. 198.

Buzzard. E. F. (1930). Lancet, 1, i.

Craig, M. (1932). Proc. int. Congr. ment. Hyg., 2, 217.

Dejerine, J. J.. and Gauckler. E. (1913). The Psychoneurases and their Treatment by Psvchntherapy, Lippincott. Philadelphia.

Emerson. W. R. P. (1910). Boston med. surg. J., 163, 326.

Flynn, J. M. (1937). Amer. J. ment. Sci., 193, 548.

Gabriel, Betty (1939). Amer. J. Orthopsychiat., 9.

Guilarowsky. W. (1937). A ilg. Z. Psychiat., 86, 56

Harris, H. I. (1939). New Engl. med. J., 221, 1

Hart, B. (1927). Psychopathologv, Macmillar, New York

Howard (1910). First Annual Report of the St. George's Tuberculosis Class, Montreal.

Jeliffe. S. E. (1918). Bosinn med. surg. J., 179, 609

Lazell, E. W. (1921). Psychnanal. Rev., 8, 168.

Marsh, L. C. (1931). Ment. Hyg., 15, 378.

Marsh, L. C. (1931). Ment.

- (1935). J. nerv. ment. Dis., 82, 381. 
Martin, A. R. (1939). Amer. J. Orthopsychiat., 9, 123.

Miller, R., and Slavson, S. (1939). Ibid., 9,79

Miller, R., and Slavson, S. (1939). Ibid., 9, 79.
Ozertzovsky, D. S. (1927). Zh. Neurpatol. Psikhiat., 20, 587.
Pratt, J. H. (1907). J. Amer. med. Ass., 49, 755.

(1907). Medical Communications of the Massachusetts Medical Society. 20,475 .

(1911) Trans. Amer. climat. Ass., 27, 87.

- (1922). Hosp. soc. Serv., 6, 401.

(1934). Int. Clin. Series, 44s., 4, 1.

Rees, J. R. (1935). Proc. roy. Soc. Med., 28, 1229.

Reik, T. (1929). Int. J. Psvcho-anal., 10, 292

Ross, E. A. (1919). Social Psychology, Macmillan, New York.
Schilder, P. (1939). Ment. Hyg., 23, 87.

Slavson, S. R. (1940). Ibid., 24, 36.

Smith, G. B. (1927). J. Amer. med. Ass., 89, 1949.

Smith, L. H. (1933). Amer. J. Psychol., 13, 33

Snowden, E. N. (1940). Lancet, 2, 769.

Sommers, M. R., and Pouppirt, P. S. (1940). Calif. West. Med., 53, 79.

Wender, L. (1936). J. nerv. ment. Dis., 84, 54.

Wittels, Fritz (1939). Amer. J. Sociol., 45, 433.

\section{LUNG TUMOURS IN MICE}

\section{INCIDENCE AS AFFECTED BY INHALATION OF CERTAIN CARCINOGENIC AGENTS AND SOME DUSTS}

- BY

\section{J. ARGYLL CAMPBELL, M.D., D.Sc.}

(From the National Institute for Medical Research, London)

In previous researches (Campbell, 1934, 1937a, 1937b, 1940) it was demonstrated that the incidence of primary lung tumours in mice may be increased by the inhalation either of tarred road dust, both with the tar and after its extraction, or of brown oxide of iron or precipitated silica, the effect being most pronounced with the tarred road dust containing tar. In continuation of these studies with the intention of seeking for stimulators or inhibitors of lung tumours, the effects of the following have been tested, and the results are given herein: (a) precipitated silica containing methylcholanthrene; $(b)$ steel grindings ; $(c)$ a mixture containing equal parts of alumina, precipitated silica, and brown oxide of iron; $(d)$ a radio-active dust from Czechoslovakia; $(e)$ a mixture containing the same three substances as $c$ plus calcium carbonate; $(f)$ a further sample of tarred road dust.

\section{Methods}

The technique employed was similar to that used in the researches cited above. For each experiment 150 mice were used-75 mice, half of each sex, for the dusted group, and 75 for the controls. Equal numbers of mice of the same colour were placed in the experimental and control groups. The mice were 3 months old, and were obtained from the mixed stock of this institute. The sexes were kept separate, and the mice placed in boxes containing eight to ten animals. The dusted mice were exposed in a closed chamber to a moderate cloud of dust once an hour for six times a day on five days each week for a year. They were allowed to complete their allotted span of life. Histological sections were made of all lungs and tracheo-bronchial lymph glands and of any organ showing pathological change.

\section{Results from Silica plus Methylcholanthrene}

The silica (British Drug Houses) was precipitated from sodium silicate by nitric acid, and was the same as that used in some of the previous experiments (Campbell, 1940, 1941). It was proved by $x$-ray analysis at the National Physical Laboratory to be amorphous and therefore without the crystal unit characteristic of quartz. During each day of dusting each box of eight to ten mice received about $500 \mathrm{mg}$. of silica dust containing $0.8 \mathrm{mg}$. of finely divided methylcholanthrene. At the beginning of the experiment a small amount of 'cholanthrene was also present. There is no way to determine aceurately the amount of the carcinogenic agent inhaled by each mouse over the whole year of dusting, but the total quantity of methylcholanthrene entering each box of mice was about $200 \mathrm{mg}$. for the whole year. The majority of the particles and clumps of particles of silica in the cloud measured less than $5 \mu$.
The dusting produced primary lung tumours in 15 $(23.8 \%)$ of the 63 mice living 10 months or longer compared with $9(13.6 \%)$ of the 66 similar control mice (Control I) - that is, the incidence is nearly doubled (Tables I and II). One of the tumours in a control mouse had an extension in the tracheo-bronchial lymph glands. Mice younger than 10 months very rarely show lung tumours, and have therefore been excluded from the calculations There is no doubt that, in mice, age is a factor in the development of pulmonary tumours. In the 15 dusted mice with tumours 8 had single tumours, 6 had two tumours, and 1 mouse had three tumours in the lungs. These numbers are few compared with those of some former experiments, and there is also a diminution in surface (pleural) area and in malignancy. On the average, in the present experiments the surface area of each tumour was only about $3.5 \mathrm{sq}$. $\mathrm{mm}$., the largest tumour being 25 sq. mm. The tumours of the control group were also few in number and small in size compared with some former controls, and it is apparent that our stock of mice has recently become more resistant to development of pulmonary or any other tumours. Although the incidence of lung tumours was doubled by the dusting, a much greater effect was expected because methylcholanthrene is one of the most potent carcinogenic agents (Twort and Twort. 1939 ; Iball, 1939), and some previous observers have obtained marked increases in the incidence of pulmonary tumours by apparently very small quantities of methylcholanthrene injected subcutaneously (Andervont, 1939; Grady and Stewart, 1939), administered by mouth (Magnus, 1939 ; Lorenz and Stewart, 1940), or injected direct into the trachea (Shimkin, 1939). In the present investigation the increase observed was of a degree to be expected by dusting with silica alone (Campbell, 1940), and it is possible that the added methylcholanthrene was present in too small a quantity or had become adsorbed to the silica particles, thus being rendered harmless. Charcoal has been found to act in this way and to hold the carcinogenic agent at the site of injection (Andervont and Lorenz, 1937); there is evidence also that in inhalation experiments carbon has an inhibitory effect (Campbell, 1939). It must be remembered, too, that different strains of mice reveal wide differences in tendency to lung tumours. For some unknown reason the mixed strain of this institute appears to have recently become more resistant in this respect. Such changes may explain why some observers have failed to produce lung tumours by direct insuffiation of carcinogenic agents into the air passages (Oberling $e t$ al., 1936, with $3: 4$-benzpyrene; Burrows, quoted by Cook et al., 1937, with $1: 2: 5: 6$-dibenzanthracene). There is no doubt that by inbreeding of mice it is possible to produce strains either very susceptible or very resistant to production of lung tumours, and in this respect heredity plays a major part.

\section{Results from Steel Grindings}

This experiment was undertaken because there is evidence of a relatively high incidence of carcinoma of the lung in metal grinders, engineers, and foundry workers (Kennaway and Kennaway, 1936; Turner and Grace, 1938), and also because dusting with brown oxide of iron increases the incidence of primary lung tumours in mice (Campbell, 1940).

The steel grindings were ohtained by grinding down caststeel files-made of high-carbon-content steel-on a corundum grinding wheel. The filings were passed through a 100-mesh filter, and the majority of the particles in the dust cloud from the resulting powder measured less than $5 \mu$. Analysis indicated that more than $75 \%$ of the dust entering the chamber was iron. There was also a certain 